\title{
INTERKULTURALNI MENADŽMENT U FINANSIJSKOM SEKTORU SRBIJE
}

\section{INTERCULTURAL MANAGEMENT IN THE FINANCIAL SECTOR OF SERBIA}

\author{
Radmila Ćurčić \\ Poslovni i pravni fakultet, Univerzitet „Union - Nikola Tesla“, Beograd, \\ Srbija
}

\section{Ljiljana Miletić}

Fakultet za projektni i inovacioni menadžment, Univerzitet „Educons“, Sremska Kamenica, Srbija

CMESTE

JEL Category: E66, R51

\begin{abstract}
Apstrakt
U globalnim uslovima poslovanja, pred liderima i menadžerima kompanija stoje mnogi izazovi, naročito u vezi menadžmenta i liderstva u multikulturalnom okruženju poslovanja. Na samom početku nastanka, glavna svrha interkulturnog menadžmenta bila je bolje upoznavanje i veće uvažavanje karakteristika drugih nacija kako bi se povećao obim poslovanja, ali je to vremenom dovelo do ostvarenja mnogo šireg cilja. Suština tog cilja je je shvatanje da su svi narodi različiti i da se njihove kulturne specifičnosti $i$ potrebe moraju uvažavati kako bi organizacije smanjile tržišne nesigurnosti i neizvesnosti poslovanja $i$ postigle konkurensku prednost na globalnom tržištu. $U$ ovom radu je prikazan odnos liderstva $i$ organizacione kulture, kao manifestacija uticaja nacionalne kulture na interkulturalni menadžment kompanije. Rezultati eksperimentalnog istaživanja odnosa lidera i zaposlenih prema dimenzijama naše nacionalne kulture, koje je sprovedenog u entitetu globalne komapanije, koja posluje u Finansijskom sektoru Srbije, prikazani su i objašnjeni u tri celine: za preduzeće u celini, uporedno za lidere i ostale zaposlene i na osnovu testiranja postavljenih hipoteza. Rezultati testiranja osnovne i pomoćnih hipoteza potvrdili su da među liderima i zaposlenima postoje razlike u odnosu prema većini dimenzija naše nacionalne kulture. To ukazuje na potrebu, da liderii kompanija sa inostranim vlasništvom, koje pos/uju na tržištu Srbije treba veću pažnju da obrate na adekvatnoj primeni Interkulturalnog menadžmenta, jer utiču na organizaciono ponašanje zaposlenih, a time $i$ na efikasnost $i$ efektivnost poslovanja organizacije.
\end{abstract}

Ključne reči: interkulturalni menadžment, liderstvo, organizaciona kultura, dimenzije nacionalne kulture.

Adresa autora zaduženog za korespodenciju:

Radmila Ćurčić

焦· radmilica.75@gmail.com 


\begin{abstract}
In global business conditions, leaders and managers of companies are exposed to many challenges, management and leadership that operates in a multicultural environment. At the very beginning, the main purpose of intercultural management was to better understand and appreciate the characteristics of other nations in order to increase the volume of business, by this time, this has led to a much wider goal. The essence of this goal is the understanding that all nations are different and that their cultural specifics and needs must be respected by leaders and managers in order to reduce organizations' market insecurity and uncertainty and achieve a competitive edge in the global market. The paper describes the relationship between the multicultural management and organizational culture, as manifested by the impact of national culture on the management of the company. Results of experimental research based on the analysis of the relationship to the dimensions of our national culture, which has conducted in the entity of the global company, operating in the Financial Sector of Serbia, are presented and explained in three parts: for the enterprise as a whole, in parallel with the leaders and other employees, and based on the testing of hypotheses. Test results of basic and auxiliary hypotheses have confirmed the hypothesis that among leaders and employees could be observed differences in relation to most of the dimensions of our national culture. This indicates that the leaders of foreignowned companies operating in the Serbian market must be more involved in the implementation of Intercultural management, because they influence the organizational behavior of employees, and hence the efficiency and effectiveness of the company's operations.
\end{abstract}

Keywords: intercultural management, leadership, organizational culture, dimensions of national culture

\section{UVOD}

Povećanje uticaja globalizacije, brisanje granica između nacionalnih ekonomija i tržišta, mnogo brža i efikasnija razmena roba ljudi, kapitala i ideja, uz razvoj interneta i novih tehnologija, doprineli su bržem protoku ljudi, znanja i informacija, kao i podizanje poslovanja kompanija na globalni nivo u uslovima intrnacionalnog radnog okruženja. To je, uslovilo i značajnije interesovanje za uticaj nacionalne kulture na organizaciono ponašanje zaposlenih i lidera, odnosno interosovanje za povećanje performansi interkulturnog menadžmenta (Bogičević Milinić, 2005). Istraživanja koja se bave savremenom teorijom i praksom menadžmenta, liderstva i organizacije, kao i primeri dobrih praksi upravljanja kulturnim razlikama prilikom sudara različitih nacionalnih kultura postaju posebno važna za konkurentno poslovanje globalnih, multinacionalnih kompanija, koje postaju stožeri savremene svetske ekonomije. U uslovima kada su procesi spajanja, preuzimanja i pripajanja kompanija deo svakodnevnice i u Srbiji, efektivno liderstvo u multikulturalnom okruženju poslovanja organizacije, kao i lideri i menadžeri koji poseduju sposobnosti, veštine $\mathrm{i}$ iskustvo u radu sa zaposlenima različitih nacionalnih kultura širom sveta postaju veoma važan resurs globalnih organizacija (Chokar, Brodbeck, \& House, 2007) i jedan od odlučujućih faktora efikasnog i efektivnog sprovođenja organizacionih promena koje su izvor njihove konkurentske prednosti na globalnom tržištu (Miletić, Karović, \& Sajfert, 2016).

\section{ODNOS LIDERSTVA I ORGANIZA- CIONOG PONAŠANJA NA GLOBALNOM NIVOU}

Lidersko vođenje organizacije, različitih timova i grupa ljudi $u$ organizaciji zasniva se na sprovođenju uticaja lidera na zaposlene, da ga dobrovoljno slede u efikasnoj i efektivnoj realizaciji organizacionih promena kako bi se realizovali postavljeni ciljevi organizacije. Uspeh procesa liderstva neposredno zavisi i ličnih karakteristika i ponašanja lidera, i zaposlenih, ali i od karakteristika poslovnog okruženja (organizaciona kultura i klima). Među karakteristikama zaposlenih od kojih zavisi efikasnost sprovođenja liderskog procesa i na koje se može uticati su: potreba za nezavisnošću i tolerantnim odnosima u međusobnom radu sa liderima i ostalim zaposlenima, želja za učešćem u odlučivanju i preuzimanje odgovornosti za realizaciju radnih zadataka, potreba razumevanja ciljeva organizacije, posedovanje znanja i iskustva, kao njihova spremnost za unapređenje znanja i postojećih veština (Miletić, Popović, \& Pavlović, 2005). S druge strane, značaj karakteristika radne sredine, među kojima su i 
nacionalna kultura, tradicija, običaji i druga raznovrsna obeležja sredine lideri i menadžeri još uvek ne uvažavaju u dovoljnoj meri, jer ne postoji potpuna saglasnost $u$ kojoj se meri na njih može unapred uticati.

Za pojam liderstva se ističe da predstavlja "sposobnost pojedinca da utiče na druge, da ih motiviše i omogući im da doprinesu efikasnosti i uspehu organizacije čiji su članovi“ (House, Hanges, Javidan, Dorfman, \& Gupta, 2004), a Yukl ističe da se većina drugih definicija liderstva zasniva na konceptu uticaja lidera na svoje sledbenike (zaposlene u organizaciji), da shvate suštinu postavljenih ciljeve i shvate in kao zajedničke i postignu in bilo da su postavljeni na nivou grupe ili čitave organizacije (Javidan, House, \& Dorfman, 2004). S obzirom na to Gardner je istražio lidersko vođenje organizacije s aspekta osnovnih funkcija (Kloppemborg, Shriberg, \& Venkatraman, 2003), sa ovakvim pristupom liderstvu, otpale su predrasude da su lideri „izvan drugih ljudi“, s obzirom na lične karakteristike koji su im potrebni.

Odnos liderstva i organizacionog ponašanja $s$ aspekta uvažavanja karakteristika različitih nacionalnih kultura, predstavlja esencijalni deo interkulturnog menadžmenta i eksplicitno je izražen rezultatima programa nazvanog „Globalni program efikasnosti liderstva $i$ organizacionog ponašanja" (GLOBE), koji je od svog početka (1993), do danas, uz već klasičnu studiju Geerta Hofstede-a (Hofstede, 2001) postao jedan od najznačajnijih istraživačkih projekata liderstva u okviru interkulturnog menadžmenta organizacije. Osnovni ciljevi ovih istraživanja je da se utvrdi5: Koje su lične karakteristike i tipična ponašanja lidera $i$ organizacione prakse opšteprihvaćene i efikasne u svim kulturama, a koje samo u nekim kulturama; Na koji način karakteristike nacionalnih i organizacionalnih kultura utiču na efektivno liderstvo, tj. na prihvatanje ponašanja, stila i vizije lidera od strane zaposlenih i na ekonomsko, fizičko i psihičko blagostanje pripadnika određenog društva; Kako se odnos prema dimenzijama nacionalnih i organizacionih kultura odražava na ponašanje zaposlenih u praksi, kao i Kakav je međusoban odnos među dimenzijama različitih nacionalnih kultura i međunarodne konkurentnosti privreda posmatranih društava.
Bez obzira na težnju da se GLOBE i sličnim istraživanjima empirijski utvrde ne samo stvarne, već i poželjne karakteristike nacionalnih i organizacionih kultura, može se reći da praktično nije mnogo napredovalo u vrednovanju dimenzija nacionalnih kultura, kako na nivou pojedinih društava (naročito tranzicionih zemalja), tako i pojedinih organizacija. Tu se misli na empirijsko utvrđivanje stvarnih i željenih shvatanja različitih dimenzija nacionalnih kultura, koje su po Hofstede-u?: 1.Distanca moći; 2.Izbegavanje neizvesnosti; 3.Humanost; 4.Institucionalni kolektivizam; 5.Grupni kolektivizama; 6.Upornost; 7.Jednakost polova; 8.Orijentacija na budućnost $\mathrm{i}$ 9.Orijentacija na rezultate.

Analiza liderstva $s$ aspekta dimenzija nacionalne kulture u čijem okruženju kompanija posluje ima za cilj stvaranje uslova da se na osnovu uvažavanja i međusobne saradnje različitih kultura obezbede uslovi za bolje razumevanje i poslovnu komunikaciju među zaposlenima različitih naroda, a na osnovu boljeg shvatanja specifičnosti drugih kultura utiče na nivo tolerantnosti $u$ organizacionom ponašanju i nivo uspešnosti interkulturalnog menadžmenta (Janićijević, 2013). Adekvatno oblikovana organizaciona kultura doprinosi smanjenju neizvesnosti poslovanja i jačanju konkurenske prednosti na osnovu boljih međuljudskih odnosa i organizacione klime koju karakteriše interesovanje zaposlenih za uvođenje inovacija, ispunjenje zahteva korisnika i stalno unapređenje kvaliteta proizvoda, kao i povećanje efikasnosti timskog rada, veća usmerenost na realizaciju ciljeva organizacije i niska fluktuacija zaposlenih (Mojić, 2011).

\section{ANALIZA DIMENZIJA NACIONAL- NE KULTURE MEĐU LIDERIMA I ZAPOSLENIMA - STUDIJA SLUČAJA U SRBIJI}

Naučna istraživanja su dokazala da liderstvo koje uvažava odnose prema dimenzijama nacionalne kulture u čijem okruženju globalne organizacije posluju ima snažan pozitivan uticaj na dugoročne performanse i povećanje efektivnosti i efikasnosti poslovanja organizacija, a time i na njenu konkurentnu prednost na globalnom tržištu. Stoga lideri i menadžeri, entiteta globalnih kompanija koje posluju na tržištu Srbije, sve više postaju svesni potrebe internog prilagođavanja liderstva i menadžmenta u skladu sa boljim uvažavanjem karakteristika mulikulturalnog okruženja u kome 
posluju. U tom cilju, u okviru studije slučaja sprovedeno je istraživanje u preduzeću Porsche leasing d.o.o. Srbija, koje se bavi pruženjem finansijskih usluga za vozila iz grupacije Porsche Srbija, a pripada Porsche Holdingu, koje je od 2011. godine u vlasništvu preduzeća Volkswagen AG iz Nemačke (najuspešnijeg proizvođača automobila Evrope), koji posredstvom ćerki firmi posluje u 10 zemalja širom sveta.

\subsection{Empirijsko istraživanje u preduzeću Porsche leasing d.o.o. Srbija}

Predmet i ciljevi empirijskog dela istraživanja odnose se na istraživanje liderstva interkulturalnog menadžmenta s aspekta dimenzijama naše nacionalne kulture u preduzeću Porsche leasing d.o.o Srbija, gde lideri višeg i srednjeg nivoa pripadaju zapadnoj (nemačkoaustrijskoj) kulturi a ostali zaposleni našoj nacionalnoj kulturi.

Osnovni cilj empirijskog dela istraživanja je, da se na osnovu studije slučaja - u entitetu globalne organizacije utvrdi, da li među liderima i zaposlenima (koji su različite nacionalne kulture) postoje razlike u opažanju i shvatanju dimenzija naše nacionalne kulture. $\mathrm{Za}$ realizaciju postavljenog cilja empirijskog dela istraživanja postavljena je jedna osnovna hipoteza :

$\mathbf{H}_{0}$ : Postoje razlike $\mathrm{u}$ odnosu na dimenzije organizacione kulture među liderima i zaposlenima u preduzeću Porsche leasing d.o.o. Srbija

i osam pomoćnih hipoteza.

$\mathbf{H}_{1}$ : Ne postoji razlika između lidera i zaposlenih u preduzeću, u odnosu na izbegavanje neizvesnosti;

$\mathbf{H}_{2}$ : Postoji razlika između lidera i zaposlenih $u$ preduzeću u pogledu distance moći;

$\mathbf{H}_{3}$ : Ne postoji razlika između lidera i zaposlenih $u$ preduzeću u pogledu koletivizma u grupi;

$\mathbf{H}_{4}$ : Postoji razlika između lidera i zaposlenih $\mathrm{u}$ preduzeću u pogledu shvatanja jednakosti polova;

$\mathbf{H}_{5}$ : Postoji razlika između lidera i zaposlenih u preduzeću u pogledu na upornost;

$\mathbf{H}_{6}$ : Postoji razlika između lidera i zaposlenih $u$ preduzeću u pogledu okrenutosti budućnosti;
$\mathbf{H}_{7}$ : Postoji razlika između lidera i zaposlenih u preduzeću u pogledu usmerenosti na rezultate;

$\mathrm{H}_{8}$ : Ne postoji razlika između lidera i zaposlenih $\mathrm{u}$ preduzeću u pogledu humanosti između lidera i zaposlenih u preduzeću

Postupak kvantitativnog istraživanja obuhvata korišćenje Upitnika o dimenzijama organizacione kulture, koji je sastavljen na osnovu malo modifikovanog GLOBE upitnika za merenje opažanja dimenzija naše nacionalne kulture među liderima i zaposlenima u posmatranom preduzeću. Za potrebe istraživanja su korišćene višestruke metode.

Kombinovani su kvalitativni i kvantitivni pristup i primenjene analitičko-sintetička, komparativna i statistička metoda. Za potrebe statističke obrade podataka korišćena je deskriptivna statistička analiza koja je obuhvatila pokazatelje centralne tendencije (aritmetičku sredinu i modus) Značajnost razlika među srednjim vrednostima ocene stavova lidera i radnika prema dimenzijama nacionalne kulture testirane su primenom t-testa, a za potrebe statističke obrade podataka korišćen je profesionalan program Statistika 12.0. Statistička analiza je obavljena za uzorak od 50 ispitanika, što obuhvata skoro sve zaposlene preduzeća. Zaglavlje upitnika obuhvata podatke o: starosti, polu, obrazovanju, radnom stažu, primanjima i broju članova domaćinstva ispitanika, sto je prikazano u Tabeli 1.

Tabela 1: Frekvenciona analiza ispitanika u preduzeću Porsche leasing d.o. Srbija

\begin{tabular}{|c|c|c|c|}
\hline Grad & $\%$ & $\begin{array}{c}\text { Starost, } \\
\text { godina }\end{array}$ & $\%$ \\
\hline Beograd & 69 & $45-65$ & 32 \\
\hline Novi Sad & 22 & $25-35$ & 30 \\
\hline Subotica & 18 & $35-45$ & 34 \\
\hline Pol & $\%$ & Obrazovanje & $\%$ \\
\hline Muški & 58 & Fakultet & 72 \\
\hline Ženski & 42 & Srednje & 28 \\
\hline $\begin{array}{c}\text { Radni staž, } \\
\text { godina }\end{array}$ & $\%$ & $\begin{array}{c}\text { Primanja, } \\
\text { RSD }\end{array}$ & $\%$ \\
\hline Preko 10 & 60 & $75000-100000$ & 40 \\
\hline 3-10 & 26 & $50000-75000$ & 48 \\
\hline Ispod 3 & 14 & $>100000$ & 12 \\
\hline
\end{tabular}


U okviru upitnika registrovana je i pozicija ispitanika u kompaniji (rukovodilac ili radnik) koja je korišćena kao kontrolna varijabla za testiranje postavljenih hipoteza istraživanja. Od 50 ispitanika iz ove privatne finansijske kompanije sa inostranim nemačko-austrijskim vlasništvom, među ispitanicima bili su predstavnici ispostava preduzeća iz tri grada Beograd (60\% ispitanika), Novi Sad (22\% isptanika ) i Subotica $(18 \%$ ispitanika).

Tabela 2: Centralne vrednosti i \% rasipanja vrednosti ocena dimenzija nacionalne kulture među liderima i zaposlenima u preduzeću u Porsche Leasing d.o.o. Srbija

\begin{tabular}{|c|c|c|c|c|c|c|}
\hline \multirow{2}{*}{$\begin{array}{l}\text { Dimenzije } \\
\text { nacionalne } \\
\text { kulture }\end{array}$} & \multirow[b]{2}{*}{ Pitanja } & \multicolumn{3}{|c|}{ Preduzeće u celini } & \multicolumn{2}{|c|}{$\begin{array}{c}\text { Srednje } \\
\text { vrednosti }\end{array}$} \\
\hline & & \begin{tabular}{|c|}
$\begin{array}{c}\text { Srednje } \\
\text { vredno- } \\
\text { sti }\end{array}$ \\
\end{tabular} & Modus & $\begin{array}{c}\% \\
\text { Varija- } \\
\text { cije }\end{array}$ & Lideri & Radnici \\
\hline \multirow{2}{*}{$\begin{array}{c}\text { I } \\
\text { Izbegavanje } \\
\text { neizvesnosti }\end{array}$} & $\begin{array}{l}\text { U našem društvu se ističu red i } \\
\text { doslednost, čak i na štetu } \\
\text { eksperimenata i inovacija }\end{array}$ & 4,96 & 5,00 & 20,75 & $5,37^{b}$ & 4,71 \\
\hline & $\begin{array}{l}\text { U našem društvu su društveni zahtevi i } \\
\text { instrukcije opisani do detalja tako da } \\
\text { građani znaju šta se od njih očekuje }\end{array}$ & 4,28 & 4,00 & 28,34 & $4,68^{a}$ & 4,03 \\
\hline \multirow{2}{*}{$\begin{array}{l}\text { II } \\
\text { Distanca } \\
\text { moći }\end{array}$} & $\begin{array}{l}\text { U našem društvu se od sledbenika } \\
\text { očekuje da prihvate odluke lidera bez } \\
\text { pogovora }\end{array}$ & 5,24 & 6,00 & 21,31 & $5,53^{a}$ & $5,06^{a}$ \\
\hline & $\begin{array}{l}\text { U našem društvu moć je koncentrisana } \\
\text { na vrhu }\end{array}$ & 6,08 & 6,00 & 15,17 & 6,11 & $6,06^{a}$ \\
\hline \multirow{2}{*}{$\begin{array}{c}\text { III } \\
\text { Institucio- } \\
\text { nalni } \\
\text { kolektivizam }\end{array}$} & $\begin{array}{l}\text { U našem društvu lideri ohrabruju } \\
\text { grupnu lojalnost, čak i na štetu } \\
\text { individualnih ciljeva }\end{array}$ & 4,50 & 5,00 & 35,70 & $4,95^{a}$ & $4,23^{a}$ \\
\hline & $\begin{array}{l}\text { U našem društvu ekonomki sistem je } \\
\text { koncipiran tako da se maksimiziraju } \\
\text { kolektivni interesi }\end{array}$ & 4,24 & 5,00 & 42,23 & $4,74^{a}$ & 3,94 \\
\hline \multirow{2}{*}{$\begin{array}{c}\text { IV } \\
\text { Kolektiviza- } \\
\text { cija u grupi }\end{array}$} & $\begin{array}{l}\text { U našem društvu deca se ponose } \\
\text { individualnim dostignućima svojih } \\
\text { roditelja }\end{array}$ & 4,88 & 5,00 & 29,46 & 3,94 & $4,32^{a}$ \\
\hline & $\begin{array}{l}\text { U našem društvu roditelji se ponose } \\
\text { individualnim dostignućima svoje dece }\end{array}$ & 5,60 & 5,00 & 15,72 & 5,79 a & $5,79^{a}$ \\
\hline \multirow{2}{*}{$\begin{array}{c}V \\
\text { Jednakost } \\
\text { polova }\end{array}$} & $\begin{array}{l}\text { U našem društvu dečaci se više } \\
\text { ohrabruju da nastave školovanje nego } \\
\text { devojčice }\end{array}$ & 4,36 & 6,00 & 40,06 & $4,79^{a}$ & $4,10^{a}$ \\
\hline & $\begin{array}{l}\text { U našem društvu je verovatnije da će } \\
\text { se na višim pozicijama na poslu naći } \\
\text { žene }\end{array}$ & 3,44 & 4,00 & 51,25 & $4,16^{b}$ & $3,00^{a}$ \\
\hline \multirow{2}{*}{$\begin{array}{c}\text { VI } \\
\text { Upornost }\end{array}$} & $\begin{array}{l}\text { Uopšteno posmatrano u našem društvu } \\
\text { ljudi su uporni }\end{array}$ & 4,60 & 5,00 & 29,46 & $4,89^{a}$ & $4,42^{a}$ \\
\hline & $\begin{array}{l}\text { U našem društvu uopšteno gledano } \\
\text { ljudi su grubi }\end{array}$ & 4,86 & 6,00 & 31,66 & 4,89 & $4,84^{a}$ \\
\hline \multirow{2}{*}{$\begin{array}{c}\text { VII } \\
\text { Okrenutost } \\
\text { budućnosti }\end{array}$} & $\begin{array}{l}\text { U našem društvu prihvaćena norma je } \\
\text { praviti planove za budućnost }\end{array}$ & 4,90 & 5,00 & 24,82 & $5,26^{a}$ & $4,68^{a}$ \\
\hline & $\begin{array}{l}\text { U našem društvu ljudi veću pažnju } \\
\text { posvećuju pravljenju planova za } \\
\text { budućnost }\end{array}$ & 4,86 & 4,00 & 24,24 & $5,47^{b}$ & $4,48^{a}$ \\
\hline \multirow{2}{*}{$\begin{array}{l}\text { VIII } \\
\text { Usmerenost } \\
\text { na rezultate }\end{array}$} & $\begin{array}{l}\text { Naše društvo podržava } \\
\text { studente/učenike da postignu izuzetne } \\
\text { rezultate }\end{array}$ & 4,44 & 5,00 & 25,80 & $5,16^{b}$ & $4,00^{a}$ \\
\hline & $\begin{array}{l}\text { U našem društvu se ljudi nagrađuju za } \\
\text { izuzetne rezultate }\end{array}$ & 4,18 & 5,00 & 33,02 & $4,89^{b}$ & $3,74^{a}$ \\
\hline $\begin{array}{c}\text { IX } \\
\text { Humanost }\end{array}$ & U našem društvu ljudi brinu o drugima & 4,54 & 5,00 & 31,84 & $5,21^{b}$ & $4,13^{a}$ \\
\hline
\end{tabular}




\subsection{Rezultati} diskusijom

istraživanja

sa

Nakon statističke obrade dobijeni rezultati istraživanja su prikazani i objašnjeni u okviru tri celine:

a. Rezultati u preduzeću u celini;

b. Uporedna analiza rezultata dobijenih među liderima i među ostalim zaposlenima i

c. Testiranje postavljenih hipoteza.

U Tabeli 2 dati su rezultati centralnih vrednosti (aritmetička sredina i modus), kao i pokazatelji rasipanja dobijene na osnovu shvatanja naše nacionalne kulture, kako za preduzeće u celini, tako i uporedno dato za lidere i ostale ostale zaposlene.

\subsubsection{Rezultati centralnih vrednosti za preduzeće u celini}

Na osnovu rezultata u tabeli 2 vidi se da se srednje vrednosti dobijenih ocena dimenzija prema našoj nacionalnoj kulturi za preduzeće u celini grupišu u intervalu 3,44 a što je najmanja vrednost dobijena na pitanje da li je u našem društvu verovatnije da će se na višim pozicijama na poslu naći žene pa do 6,08 što je najveća vrednost dobijena na pitanje „u našem društvu moć je koncentrisana na vrhu“ što pokazuje da $u$ našem društvu postoji polarizacija po pitanju jednakosti polova, da će se retko na višim pozicima naših preduzeća, pa i inostranih naći žene lideri, kao i da je velika centralizacija, sa koncentracijom moći u vrhu, što ukazuje da će zaposleni pre bez pogovora sprovoditi odluke lidera, nego dovesti u pitanje njegov stav lidera, kada se sa njim ne slažu.

$\mathrm{Na}$ osnovu vrednosti modusa vidi se da su za većinu pitanja najčešće ocene 5 ili 6 , dok je najniža vrednost učestalosti (4), koja je dobijena za: Izbegavanje neizvesnosti, Okrenutost budućnosti i Usmerenost na rezultate. Što se tiče koncentracije uzoraka i rasipanja ocena, na osnovu \% varijacije (manje vrednosti pokazuje veće grupisanje), najmanja vrednost je dobijena za Distancu moći i za Kolektivizam u grupi, što ukazuje da su se ispitanici u velikoj meri složili oko ovoga.

Nasuprot ovom, najveće neslaganje je uočeno za Jednakost polova. Kompletni rezultati za preduzeće u celini su dati u Tabeli 3.

Tabela 3: Pokazatelji rezultata shvatanja naše kulture za preduzeće u celini

\begin{tabular}{|c|c|l|}
\hline R.broj & Dimenzije kulture & \multicolumn{1}{c|}{ Preduzeće u celini } \\
\hline I & $\begin{array}{c}\text { Izbegavanje } \\
\text { neizvesnosti }\end{array}$ & $\begin{array}{l}\text { U preduzeću od strane lidera ne podstiče kreativnost i inovacije, a } \\
\text { time i osposobljavanje podređenih da se hrabrije uključe u promene }\end{array}$ \\
\hline II & Distanca moći & $\begin{array}{l}\text { U našem društvu se od sledbenika očekuje da prihvate odluke } \\
\text { lidera bez pogovora i da je u našem društvu moć koncentrisana na } \\
\text { vrhu }\end{array}$ \\
\hline III & $\begin{array}{l}\text { Institucionalni } \\
\text { kolektivizam }\end{array}$ & $\begin{array}{l}\text { U u našem društvu lideri ohrabruju grupnu lojalnost, čak i na štetu } \\
\text { individualnih ciljeva i da u našem društvu ekonomski sistem je } \\
\text { koncipiran tako da se maksimiziraju kolektivni interesi. }\end{array}$ \\
\hline IV & $\begin{array}{c}\text { Kolektivizam u } \\
\text { grupi }\end{array}$ & $\begin{array}{l}\text { U našem društvu deca ponose individualnim dostignućima svojih } \\
\text { roditelja i da se roditelji ponose individualnim dostignućima svoje } \\
\text { dece. }\end{array}$ \\
\hline VI & $\begin{array}{c}\text { Jednakost polova } \\
\text { Upornost }\end{array}$ & $\begin{array}{l}\text { U našem društvu dečaci se više ohrabruju da nastave školovanje } \\
\text { naći žene. }\end{array}$ \\
\hline VII & $\begin{array}{l}\text { Okrenutost } \\
\text { budućnosti }\end{array}$ & $\begin{array}{l}\text { U neruje se da se na višim pozicijama na posmatrano u našem društvu ljudi su uporni i grubi } \\
\text { budućnost, kao i da ljudi pažnju posvećuju pravljenju planova za } \\
\text { budućnost. }\end{array}$ \\
\hline VIII & $\begin{array}{c}\text { Usmerenost na } \\
\text { rezultate }\end{array}$ & $\begin{array}{l}\text { Naše društvo podržava studente/učenike da postignu izuzetne } \\
\text { rezultate i u našem društvu ljudi se nagrađuju za izuzetne rezultate }\end{array}$ \\
\hline IX & Humanost & Naše društvo je u principu humano \\
\hline
\end{tabular}




\subsubsection{Rezultati centralnih vrednosti među liderima i zaposlenima}

$\mathrm{Na}$ osnovu dobijenih rezultata srednjih vrednosti (tabela 2) uočava se sledeće:

- I - lideri na višem nivou nego radnici $(5,37 ; 4,71)$ smatraju da se u našem društvu ističu red i doslednost, čak i na štetu eksperimenata i inovacija;

- $\quad$ II - u našem društvu moć je koncentrisana na vrhu $(6,11 ; 6,06)$,

- IV - u našem društvu deca se ponose individualnim dostignućima svojih roditelja $(5,79 ; 4,32)$,

- V - u našem društvu verovatnije je da će se na višim pozicijama na poslu nađu žene $(4,16 ; 3,00)$,

- VII - u našem društvu ljudi veću pažnju posvećuju pravljenju planova za budućnost $(5,47 ; 4,48)$,

- VIII - u našem društvu nagrađuju se ljudi za izuzetne rezultate $(5,16 ; 4,00)$,

- $\quad$ IX - u našem društvu ljudi brinu o drugima $(5,2 ; 4,12)$.
Što se tiče rezultata za odnos prema linstitucionalnom kolektivizmu (III) i Upornosti (VI), na osnovu srednje vrednosti uočava se da nema razlike $(5 ; 5)$.

Uporedna analiza rezultata shvatanja naše kulture među liderima $\mathrm{i}$ zaposlenim $\mathrm{u}$ posmatranom preduzeću histogramski je data na slici 1.

\subsubsection{Rezultati testiranja postavljenih hipoteza}

Rezultati testiranja hipoteza dobijeni su primenom T-TESTA, a na osnovu testiranja značajnosti razlika srednjih vrednosti i distribucija dobijenih odgovora, tako da postoji značajna razlika kada je verovatnoća manja od 0,05 , odnosno ukoliko je verovatnoća manja od 0,01 , razlika je visokoznačajna, što znači da se sa verovatnoćom $\mathrm{P}=0,99$ može prihvatiti hipoteza. Na bazi rezultata primene T-testa može se prihvatiti osnovna hipoteza $\mathrm{H}_{\circ}$ da među liderima i zaposlenima $\mathrm{u}$ preduzeću Porsche leasing d.o.o. Srbija postoji razlika u odnosu na dimenzije organizacione kulture, kao i da se mogu prihvatiti pomoćne hipoteze.

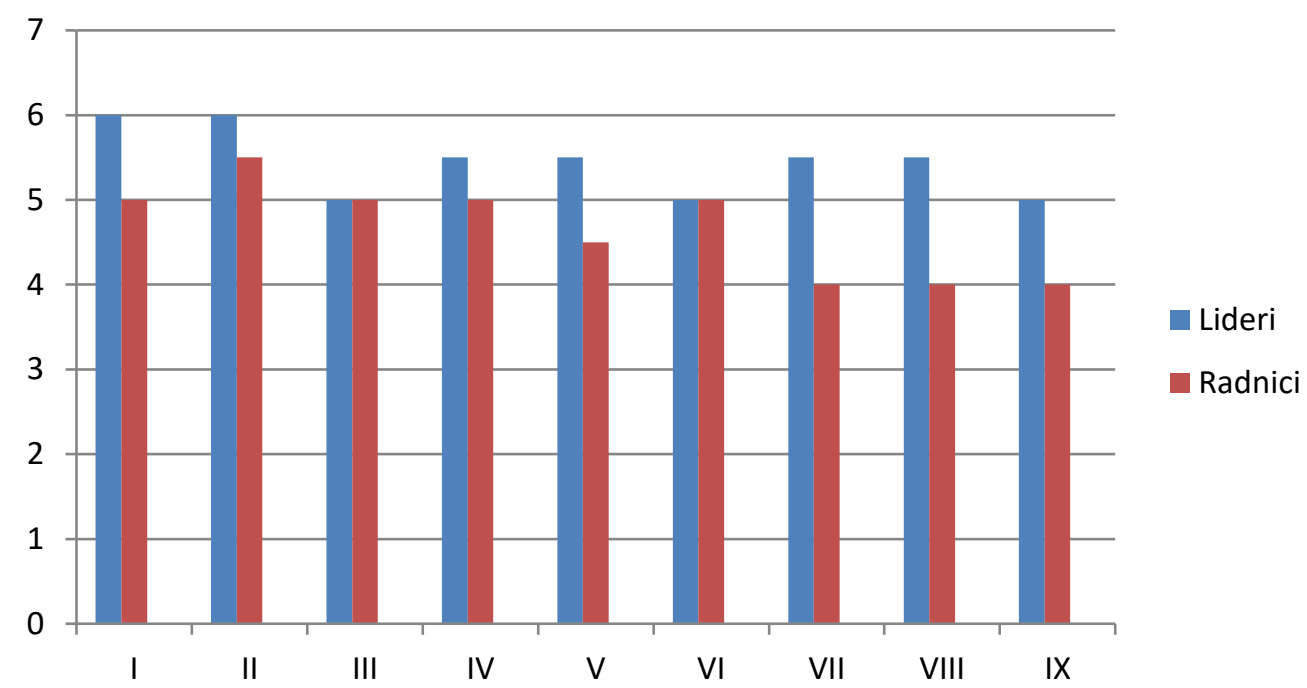

Slika 1: Uporedna analiza rezultata dobijenih među liderima i među radnicima

\section{ZAKLJUČAK}

Razvoj društva u svim segmentima je u neposrednoj vezi sa promenom sistema vrednosti, što u globalnom poslovanju i post-tranzicionom poslovanju podrazumeva i bolje razumevanje lidera i menadžera i zaposlenih različitih kultura. $U$ ovom radu akcenat rada je bio na teorijsko $i$ praktično istraživanje liderstva i odnosa interkulturalnog menadžmenta i organizacione kulture u globalnoj kompaniji sa inostranim vlasništvom, koja posluje u Finansijskom sektoru Srbije. Dobijeni rezultati eksperimentalne analize liderstva $s$ aspekta naše nacionalne kulture pokazuju da među liderima i zaposlenima u preduzeću Porsche Leasing d.o.o postoje razlike u shvatanju dimenzija naše nacionalne kulture. Naime lideri, na značajno višem nivou nego radnici smatraju da se u našem društvu: ističu red i doslednost, čak i na štetu eksperimenata i 
inovacija, da se deca ponose individualnim dostignućima svojih roditelja, da se verovatnije žene neće naći na višim pozicijama na poslu, da se veća pažnja posvećuje pravljenju planova za budućnost, da se studenti/učenici podržavaju ka postizanju rezultata i ljudi nagrađuju za izuzetne rezultate, kao i da ljudi našeg društva brinu o drugima. $U$ cilju podrke široj primeni interkulturalnog menadžmenta $u$ entitetima globalnih kompanija koje posluju na tržištu Srbije neophodno je sprovesti šire istraživanje na većem broju kompanija kako bi se proverili dobijeni rezultati, dobijeni na osnovu ove studije slučaja.

\section{CITIRANA DELA}

Bogičević Milinić, B. (2005). The influence of culture human resorce management processes and practices: The proposition for Serbia. Economic Anals, 54(181), 93-118. doi:10.2298/EKA0981093B

Chokar, J. S., Brodbeck, F. C., \& House, R. J. (Urednici). (2007). Culture and leadership across the World: the GLOBE book of in-depth studies of 25 societies. Mahwah, NJ; London: Lawrence Erlbaum Associates.

Hofstede, G. (2001). Culture's Consequences: Comparing Values, Behaviors, Institutions, and Organizations Across Nations. Thousand Oaks, CA: SAGE Publications.

House, R., Hanges, P., Javidan, M., Dorfman, P., \& Gupta, V. (Urednici). (2004). Culture, Leadership, and Organizations: The GLOBE Study of 62 Societies. Thousand Oaks, CA: Sage Publications.

Janićijević, N. (2013). Organizaciona kultura i menadžment. Beograd: Ekonomski fakultet.

Javidan, M., House, R., \& Dorfman, P. (2004). A nontechnical summary of GLOBE findings", In: House, R. J. et al. (Eds.), , SAGE Publications, Thousand Oaks, CA, 2004,. U R. House, P. Hanges, M. Javidan, P. Dorfman, \& V. Gupta, Culture, Leadership, and Organizations: The GLOBE Study of 62 Societies (str. 29-48). Thousand Oaks, Calif: Sage Publ.

Kloppemborg, J. T., Shriberg, A., \& Venkatraman, J. (2003). Project Leadership (The Project Management Essential Library). Vienna, VA: Berrett-Koehler Publishers.

Miletić, L., Karović, S., \& Sajfert, Z. (2016). Liderstvo u projektnom menadžmentu - teorija i praksa. Zrenjanin: Tehnički fakultet "Mihajlo Pupin.

Miletić, L., Popović, B., \& Pavlović, N. (2005). Organizaciona ponašanja. Novi Sad: Viša poslovna škola u Novom Sadu.

Mojić, D. (2011). Savremena interkulturna istraživanja organizacija: projekat GLOBE. Ekonomski horizonti, 13(2), 71-87.

Datum prve prijave:

13.03.2018.

Datum prijema korigovanog članka:

Datum prihvatanja članka:
20.07.2018.

05.09.2018.

Kako citirati ovaj rad? / How to cite this article?

Style - APA Sixth Edition:

Ćurčić, R., \& Miletić, L. (2018, 10 15). Interkulturalni menadžment u finansijskom sektoru Srbije. (Z. Čekerevac, Ur.) FBIM Transactions, 6(2), 10-18. doi:10.12709/fbim.06.06.02.02 
Style - Chicago Sixteenth Edition:

Ćurčić, Radmila, i Ljiljana Miletić. 2018. „Interkulturalni menadžment u finansijskom sektoru Srbije.“ Urednik Zoran Čekerevac. FBIM Transactions (MESTE) 6 (2): 10-18. doi:10.12709/fbim.06.06.02.02.

Style - GOST Name Sort:

Ćurčić Radmila i Miletić Ljiljana Interkulturalni menadžment u finansijskom sektoru Srbije [Časopis] // FBIM Transactions / ur. Čekerevac Zoran. - Beograd : MESTE, 1510 2018. - 2 : T. 6. - str. 10-18.

Style - Harvard Anglia:

Ćurčić, R. \& Miletić, L., 2018. Interkulturalni menadžment u finansijskom sektoru Srbije. FBIM Transactions, 15 10, 6(2), pp. 10-18.

Style - ISO 690 Numerical Reference:

Interkulturalni menadžment u finansijskom sektoru Srbije. Ćurčić, Radmila i Miletić, Ljiljana. [ur.] Zoran Čekerevac. 2, Beograd : MESTE, 1510 2018, FBIM Transactions, T. 6, str. 10-18. 